\title{
OS BOLETINS DA COMISSÃ̃ BRASILEIRO-AMERICANA DE EDUCAÇÃO INDUSTRIAL NA DIVULGAÇÃO DE SABERES PEDAGÓGICOS E DISCIPLINARES
}

\author{
Oscar Silva Neto \\ Universidade Federal de Santa Catarina \\ oscarsilvaneto@hotmail.com \\ David Antonio da Costa \\ Universidade Federal de Santa Catarina \\ david.costa@ufsc.br
}

\begin{abstract}
RESUMO
O presente trabalho pretende caracterizar os Boletins da Comissão Brasileiro-Americana de Educação Industrial (CBAI) como materiais para o ensino de Matemática nas Escolas Industriais do Brasil. O objetivo é discorrer sobre como estes Boletins podem ser encarados como instrumentos que explicitam propostas de ensino espelhados nas vagas pedagógicas de um tempo. O corpus da pesquisa foram os Boletins cedidos aos autores datados de 1948, 1951 e 1952. Como os impressos tinham a intenção de trazer orientações pedagógicas aos docentes do ensino industrial, verifica-se que a Matemática ocupava lugar de destaque e que algumas orientações para o seu ensino foram deixadas registradas nos Boletins impressos, fazendo com que o professor fizesse associação de sua aula com a oficina.
\end{abstract}

Palavras-chave: Boletins. Ensino Industrial. Matemática.

\section{THE BULLETINS OF THE BRAZILIAN-AMERICAN COMMISSION OF INDUSTRIAL EDUCATION IN THE DISSEMINATION OF PEDAGOGICAL AND DISCIPLINARY KNOWLEDGE}

\begin{abstract}
The present paper intends to characterize the Bulletins of the Brazilian-American Commission of Industrial Education (CBAI) as materials for the teaching of Mathematics in the Industrial Schools of Brazil. The objective is to discuss how these Bulletins can be seen as instruments that explain teaching proposals mirrored in the pedagogical positions of a time. The corpus of the research were the Bulletins assigned to the authors dated 1948, 1951 and 1952. As the printed ones had the intention to bring pedagogical guidelines to the teachers of the industrial education, it turns out that Mathematics occupied a prominent place and that some orientations for the his teaching was left recorded in the printed Bulletins, causing the teacher to make an association of his class with the workshop.
\end{abstract}

Keywords: Bulletins. Industrial Education. Mathematics. 


\section{LOS BOLETINES DE LA COMISIÓN BRASILEÑO-AMERICANA DE EDUCACIÓN INDUSTRIAL EN LA DIVULGACIÓN DE CONOCIMIENTOS PEDAGÓGICOS Y DISCIPLINARIOS}

\section{RESUMEN}

El presente trabajo pretende caracterizar los Boletines de la Comisión Brasileño-Americana de Educación Industrial (CBAI) como materiales para la enseñanza de Matemáticas en las Escuelas Industriales de Brasil. El objetivo es discurrir sobre cómo estos Boletines pueden ser encarados como instrumentos que explicitan propuestas de enseñanza reflejadas en las vacantes pedagógicas de un tiempo. El corpus de la investigación fueron los Boletines cedidos a los autores datados de 1948, 1951 y 1952. Como los impresos tenían la intención de traer orientaciones pedagógicas a los docentes de la enseñanza industrial, se verifica que la Matemática ocupaba un lugar destacado y que algunas orientaciones para el su enseñanza fueron dejadas registradas en los Boletines impresos, haciendo que el profesor hiciera asociación de su clase con el taller.

Palabras clave: Boletines. Enseñanza Industrial. Matemáticas.

\section{LES BULLETINS DE LA COMMISSION AMÉRICANO-BRÉSILIENNE D'ÉDUCATION INDUSTRIELLE DANS LA DIFFUSION DES CONNAISSANCES PÉDAGOGIQUES ET DISCIPLINAIRES}

\section{RÉSUMÉ}

Le présent document a pour objet de caractériser les Bulletins de la Commission américanobrésilienne pour l'éducation industrielle (CBAI) en tant qu'aide l'enseignement des mathématiques dans les écoles industrielles du Brésil. L'objectif est de discuter de la façon dont ces bulletins peuvent être considérés comme des instruments expliquant les propositions d'enseignement reflétées dans les positions pédagogiques d'une époque. Le corpus de la recherche était constitué des Bulletins des auteurs datés de 1948, 1951 et 1952. Comme les imprimés visaient à donner des directives pédagogiques aux enseignants de l'enseignement industriel, il s'avère que les mathématiques ont été mises en évidence et que certaines orientations pour l'enseignement a été laissée dans les bulletins imprimés, ce qui a amené l'enseignant à associer son curs à l'atelier.

Mots-clés : Bulletins. Éducation Industrielle. Mathématiques.

\section{INTRODUÇÃO}

Este trabalho faz parte de uma pesquisa de doutorado em andamento cujo tema principal está ligado aos conhecimentos matemáticos - em particular de aritmética - relacionados às instituições de ensino industrial no Brasil. Estudos como estes fazem parte do GHEMAT Brasil (Grupo Associado de Estudos e Pesquisas sobre História da Educação Matemática), fundado em 
13 de abril de 2018 e do GHEMAT-SC (Grupo de Pesquisa de História da Educação Matemática

- Santa Catarina) e relacionam-se, como o próprio nome descreve, ao campo de estudos denominado História da Educação Matemática, que toma como “objeto de investigação historiográfica todas as práticas educativas mobilizadoras de cultura matemática em quaisquer contextos de atividade humana, dentre eles, sobretudo, os contextos educativos escolares" (MIGUEL, 2014, p. 31).

Apesar de que o I ENAPHEM (Encontro Nacional de Pesquisa em História de Educação Matemática) tenha ocorrido somente em 2012, as primeiras pesquisas brasileiras neste campo de estudos datam dos anos de 1980 (MIGUEL, 2014). Além disso, o papel que a História da Educação Matemática vem desempenhando merece destaque, uma vez que “[...] agir sobre o presente significa, antes de qualquer coisa, compreender como e de que modo a matemática se colocou como objeto de ensino e quais modos de ensiná-la foram preconizados" (FLORES, 2014, pp. 5354).

Porém, para a escrita desta história, as fontes se tornam necessárias. Mas quais fontes poderiam ser utilizadas? - questionaria o leitor.

Livros antigos de matemática? Manuais para professores ensinarem matemática? Cadernos de matemática de professores e alunos? Programas e orientações curriculares para o ensino de matemática, elaborados em outras épocas? Boletins escolares com notas de matemática? Diários de classe? Depoimentos de antigos mestres? Testemunhos de alunos de cursos de matemática? Leis e decretos sobre o ensino de matemática? Provas antigas de matemática? Um conjunto de sólidos geométricos de madeira para o ensino de geometria no curso primário? Tabelas e mapas ilustrados para o ensino de aritmética? Blocos lógicos? É possível continuar essa série de interrogações e a todas elas responder sim (VALENTE, 2013, pp. 44-45).

Percebe-se a variedade de fontes que os pesquisadores lançam mão para a produção e escrita de uma história da educação matemática. Não citadas no excerto acima, mas não menos importantes, as revistas pedagógicas e as publicações periódicas de um modo geral também são tidas como fontes para a pesquisa no campo. De acordo com Borges (2014), "A imprensa pedagógica apresenta aspectos que admitem uma melhor compreensão da História da Educação e do Ensino, como também o conhecimento da cultura interior aos estabelecimentos escolares, o que proporciona diversas vantagens ao historiador $[\ldots]$ ”. 
Neste sentido, o trabalho tem foco centrado nos Boletins impressos pela Comissão Brasileiro-Americana de Educação Industrial (CBAI). Para Bastos (2007),

Jornais, boletins, revistas, magazines - feitas por professores para professores, feitas para alunos por seus pares ou professores, feitas pelo Estado ou outras instituições como sindicatos, partidos políticos, associações de classe, Igrejas contêm e oferecem muitas perspectivas para a compreensão da história da educação e do ensino. Sua análise possibilita avaliar a política das organizações, as preocupações sociais, os antagonismos e as filiações ideológicas, além das práticas educativas e escolares (BASTOS, 2007, p. 167).

Além disso, a autora ainda enfatiza que estes periódicos são fontes privilegiadas de pesquisa, "pois fazem circular informações sobre o trabalho pedagógico, o aperfeiçoamento das práticas docentes, o ensino específico das disciplinas, a organização dos sistemas, as reivindicações da categoria do magistério e outros temas que emergem do espaço profissional" (Ibid., p. 167).

Corroborando com a autora, Melo (2017) também deixa claro que:

A imprensa periódica é uma fonte interessante de estudo no campo da História da Educação, abrange jornais, revistas, boletins, entre outros, direcionados à um público a partir de uma dada intencionalidade e objetivo, seja informar, noticiar, entreter, divulgar opinião, comercializar, entre outros. A imprensa seja a educacional, direcionada em especial a professores e profissionais da educação, seja a não diretamente educacional que aborda questões diversas da realidade social, registram o passado e ideologias, tornando-se um rico material para a investigação do momento histórico em que foi produzida. (MELO, 2017, p. 24182).

Quando da realização do XI ENEM (Encontro Nacional de Educação Matemática), no ano de 2017, Costa (2017) fez uma análise das fontes históricas que vêm sendo utilizadas pelos historiadores da educação matemática. Para ele,

Muito semelhantemente os arquivos públicos, as revistas pedagógicas, os cadernos escolares, jornais com a veiculação de notícias e as produções acadêmicas dos personagens investigados ou de programas de pós-graduação stricto sensu são identificados como as fontes menos frequentes nos estudos analisados. (COSTA, 2017, p. 34).

Esse panorama traçado pelo autor mostra que os tipos de fonte como jornais, revistas e impressos precisam ser mais visitados pelos historiadores, pois produzem conhecimentos 
relevantes para as pesquisas. Apesar de pouco utilizados, os impressos pedagógicos têm sua importância reconhecida pela literatura na área da História da Educação Matemática. Assim escreve Gomes (2016, p. 130): “Em História da Educação Matemática, o conhecimento de pesquisas já concluídas, documentos legislativos, programas de ensino, materiais didáticos e escolares, impressos pedagógicos, entre outros, torna-se indispensável".

Ao analisar um trabalho, Garnica (2010) identifica uma ampliação da utilização de fontes escritas e a produção de novas fontes. Assim diz o autor:

Miorim identifica, nesse segundo período, um interesse pela introdução de novas fontes ("além de documentos oficiais e de textos de natureza variada produzidos por personagens de destaque, começam a ser utilizados outros documentos escritos, como biografias, arquivos pessoais de personalidades, revistas e jornais, bem como aqueles produzidos pelas instituições escolares - arquivos, provas, fichas de alunos, históricos escolares, diários de classe e cadernos escolares (GARNICA, 2010, p. 277).

Nas metodologias de pesquisa com jornais e impressos pedagógicos, há de se considerar as potencialidades e limitações que o trabalho pode trazer. Porém, abre-se a porta para novos protocolos de investigação.

Ao articular entrevistas, documentos escritos, fotografias, jornais escolares e documentos pessoais - criou-se um protocolo investigativo multifacetado do qual aqui são ressaltados, de modo específico, o trabalho com arquivos escolares e aspectos próprios ao uso da história oral (SOUZA; GARNICA, 2013, p. 763).

Considerar-se-á, portanto, para esta pesquisa, os Boletins da CBAI como sendo materiais para o ensino, instrumentos que melhor possam, com o seu uso pelo docente e/ou pelos alunos, explicitar propostas de ensino que em vagas pedagógicas de um tempo se espelham.

A análise parte de um conjunto de Boletins da CBAI que foram digitalizados e repassados pelo Professor Mário Lopes Amorim à Professora Bárbara Winiarski Diesel Novaes, ambos da UTFPR. Esta última fez a gentileza de repassar aos autores as cópias digitalizadas dos mesmos. Foram analisados os exemplares de abril/1948, abril e julho/1951 e novembro/1952, pois até o presente momento, foram os primeiros que aos autores foram repassados. Ainda não se teve acesso aos demais Boletins. 
Assim sendo, buscou-se responder à seguinte questão: Quais saberes pedagógicos e disciplinares emergem dos Boletins da CBAI, considerados estes como dispositivos para o ensino de Matemática nas Escolas Industriais?

\section{OS BOLETINS DA CBAI}

A CBAI (Comissão Brasileiro-Americana de Educação Industrial) surgiu a partir de um acordo entre os governos do Brasil e dos Estados Unidos, numa ação resultante da I Conferência de Ministros e Diretores da Educação das Repúblicas das Américas, realizada em 1943, em Havana. Tal acordo tinha a função de realizar

um programa de cooperação educacional, visando a uma maior aproximação entre os dois países, mediante intercâmbio de educadores, ideias e métodos pedagógicos, acordo esse assinado a 3 de janeiro de 1946, pelo Ministro da Educação, Raul Leitão da Cunha, representando o Brasil, e pelo Sr. Kenneth Holland, Presidente da Inter-American Educational Foundation, Inc., em nome dos Estados Unidos (FONSECA, 1986, p. 99).

Em resumo, pode-se dizer que a CBAI é um

[...] programa de cooperação firmado entre os governos do Brasil e dos Estados Unidos em 1946, com o objetivo de formar professores para atuar no Ensino Industrial, numa conjuntura em que o Brasil vinha experimentando um processo de expansão industrial, que se esboçava desde a década de 1930, aliada à crescente preocupação dos Estados Unidos com a América Latina, já observada durante a Segunda Grande Guerra, e ampliada com a irrupção da Guerra Fria. A CBAI pode ser tomada como um exemplo concreto da influência exercida por concepções educacionais elaboradas nos E.U.A. sobre a educação brasileira no pós-guerra, que apontariam para a superação do subdesenvolvimento na América Latina (AMORIM, 2007, p. 151).

Nos doze pontos do programa de ação desenvolvido pela CBAI, o primeiro deles era o de "Desenvolvimento de um Programa de treinamento e aperfeiçoamento de professores, instrutores e administradores" (FONSECA, 1986, p. 101). Junto com estes, outros onze pontos tinham a intenção de dar melhores condições ao ensino industrial brasileiro.

Outro ponto que chama a atenção para esta pesquisa é o de número 4, in verbis: "Ampliação dos serviços de bibliotecas; verificar a literatura técnica existente em espanhol e 
português; examinar a literatura técnica existente em inglês e providenciar sobre a aquisição e tradução das obras que interessarem ao nosso ensino industrial” (Ibid., p. 101).

E, nesse sentido, o próprio autor coloca que, em meio ao desenvolvimento de professores e técnicos, surgia o que passou a ser chamado de "Boletim da CBAI".

Ao mesmo tempo iniciava aquela Comissão um amplo programa de tradução de obras técnicas, assim como a publicação mensal de um Boletim, relativo às atividades do ensino industrial de um modo geral, o que constituía, sem dúvida, a primeira experiência realizada no Brasil naquele sentido (Ibid., p. 105).

Mas e os boletins? O que eram? Matérias a respeito da CBAI eram publicadas nos chamados "Boletins da CBAI", que passaram a ser publicados em janeiro de 1947 e deixaram de ser impressos em junho de 1961. "Legislação federal de ensino, cultura técnica, administração escolar, notícias do Ministério e notícias das escolas da rede federal compunham as matérias recorrentes no Boletim” (CUNHA; FALCÃO, 2009, p. 162 apud PROHMANN, 2016, p. 99). Segundo Pinto e Novaes (2008, p. 748), os Boletins “forneciam orientações didático-pedagógicas às escolas técnicas do país".

Uma das intenções dos Boletins era divulgar os feitos da Comissão entre os industriais e os dirigentes do ensino industrial. De acordo com Bordignon (2013),

Os boletins demonstraram, basicamente, a imposição da ideologia das classes dominantes por meio da educação técnica e trouxeram uma carga muito grande de informações acerca do projeto de cidadão-trabalhador que se imaginava para 0 país. A formação de trabalhadores para as fábricas de um país que se industrializava ultrapassava os limites da aprendizagem de uma profissão; a questão posta ali, claramente, foi também a formação moral de indivíduos que deveriam ser nivelados e classificados para obedecer à ordem. O Estado brasileiro atuou no sentido de providenciar a formação de técnicos para o projeto desenvolvimentista e em benefício da acumulação do capital, para além da formação profissional no modelo liberal. Buscou a formação moral, ideológica e cultural inspirada pelas agências externas e no modelo de sociedade norteamericano (BORDIGNON, 2013, p. 3).

De acordo com Maciel (2018, p. 81), “A publicação dos boletins chegou a um total de 150 edições, sendo a primeira datada de janeiro de 1947 e a última de junho de 1961". Depois de um certo tempo, a publicação mensal foi perdendo sua regularidade. Apesar de existirem muitos boletins, não há, na pesquisa referenciada, a análise da coleção completa. 
É importante ressaltar, porém, que apesar da significativa quantidade de boletins encontradas em visitas às instituições, ela não constitui a coleção completa destes boletins. A relação de Boletins da CBAI encontrados foi dos anos de: 1948 (10 edições), 1951 (10 edições), 1952 (11 edições), 1954 (11 edições), 1955 (12 edições), 1956 (12 edições) 1957 ( 2 edições), 1958 (3 edições), 1959 (11 edições), 1960 (9 edições), 1961(9 edições). Destes Boletins, aqueles referentes aos anos de 1948, 1951 e 1952 estão presentes no DEDHIS (UTFPR), porém não eram os Boletins originais e sim cópias, por isso não foi possível saber qual o estado de conservação e tampouco se existem os Boletins originais datados destes anos. Os Boletins que datam de 1954, 1956, 1959, 1960 e 1961 estão presentes na Biblioteca da Faculdade de Educação da USP, que se encontram armazenados em estado razoável de conservação (PROHMANN, 2016, p. 99).

Para melhor compreensão do leitor, segue uma imagem de um dos Boletins da CBAI, especificamente o de julho de 1951.

FIGURA 1 - Boletim da CBAI de julho de 1951

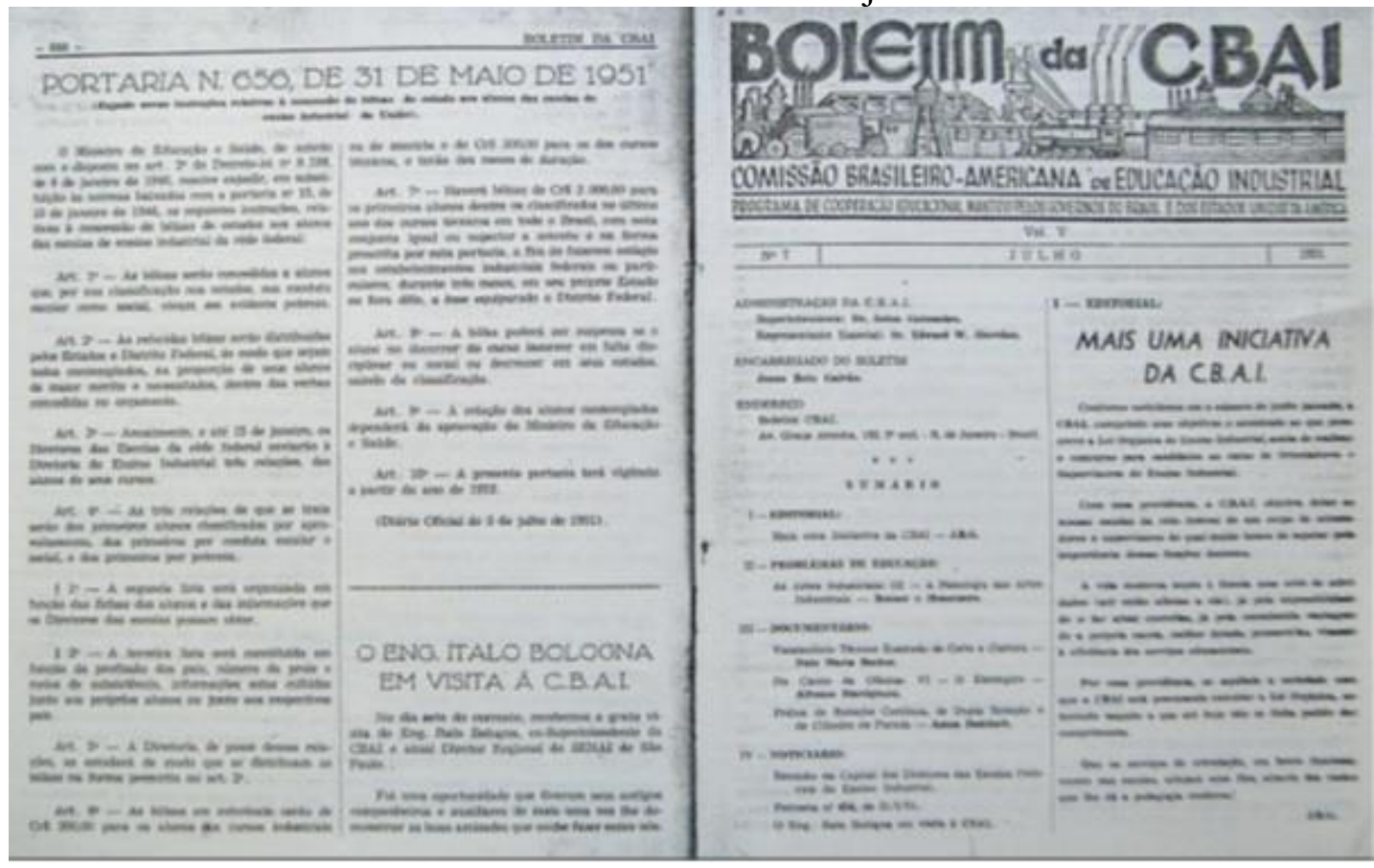

Fonte: Museu Virtual da UTFPR

Na capa do Boletim, o cabeçalho aparecia com o título "Boletim da CBAI", seguido da descrição "Comissão Brasileiro-Americana de Educação Industrial” e, mais abaixo, com a explicação que dizia: "Programa de cooperação educacional mantido pelos governos do Brasil e dos Estados Unidos da América". Ainda, abaixo, havia a descrição do volume, número do boletim, mês e ano da publicação. A figura abaixo ilustra o cabeçalho de um dos Boletins:

Rev. Iberoam. Patrim. Histórico-Educativo, Campinas (SP), v. 5, p. 1-17, e019035, 2019. 
FIGURA 2 - Cabeçalho do Boletim da CBAI de Julho de 1951

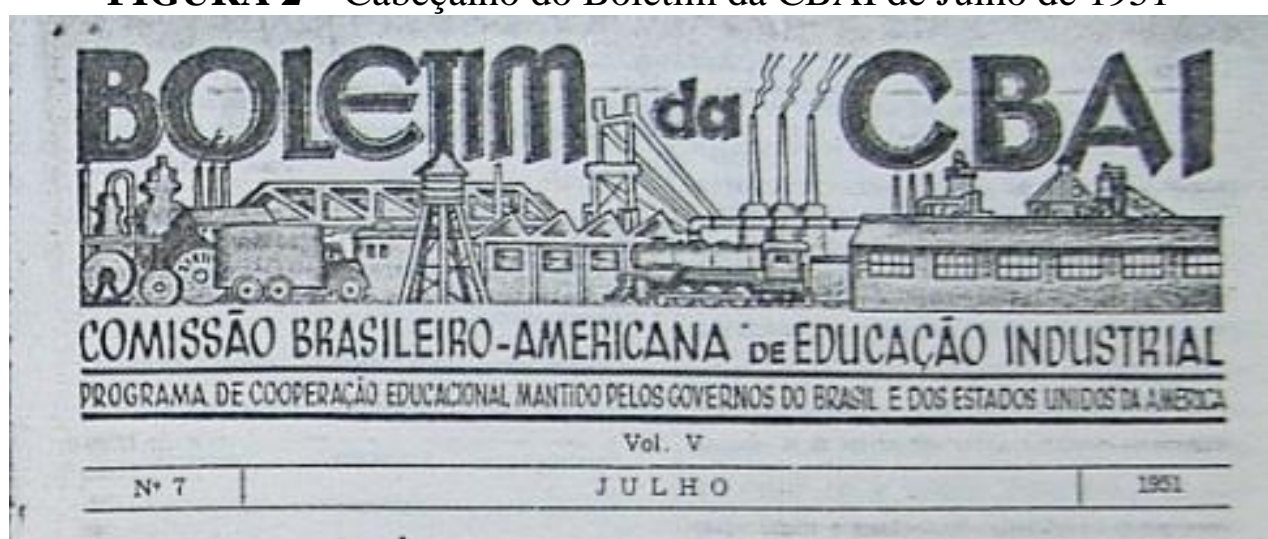

Fonte: Museu Virtual da UTFPR

Ainda na capa, apareciam os dados referentes à Administração da CBAI, ao encarregado do Boletim, bem como o endereço. No Sumário, pode-se perceber a divisão do Boletim em sessões. Eram geralmente 4 (quatro) as que constavam nos Boletins: I - Editorial; II - Problemas de Educação; III - Documentário e; IV - Noticiário.

Desta maneira, os autores procederam a leitura de todos os artigos e extraíram as orientações referentes ao ensino de matemática para as Escolas Industriais da época, ou seja, o que se fez foi tentar encarar os Boletins da CBAI como instrumentos/materiais/dispositivos para o ensino de Matemática em tempos de Ensino Industrial no Brasil.

\section{BOLETINS DA CBAI: CONDENSANDO SABERES PEDAGÓGICOS E DISCIPLINARES}

Como visto acima, nos Boletins da CBAI havia orientações didático-pedagógicas para as escolas técnicas do país. Nesta pesquisa, interessam as que dizem respeito à Matemática. Assim sendo, passa-se a analisar os conteúdos dos Boletins que dizem respeito a essa área do conhecimento. Registre-se que a bibliografia de Matemática voltada para o ensino industrial era bastante escassa.

Esta afirmação é feita por Arlindo Clemente, professor da Escola Técnica Nacional, que escrevia artigos nos Boletins da CBAI. Na Edição de Volume II, N. 4, de abril de 1948, Clemente assim escreve: "Bibliografia lamentavelmente pobre é a nossa" (p. 86). Há, neste Boletim, um primeiro artigo que se pode ser interpretado como um saber pedagógico e disciplinar, ou seja, é o Boletim da CBAI servindo de apoio ao professor de matemática. 
FIGURA 3 - Boletim da CBAI de abril de 1948

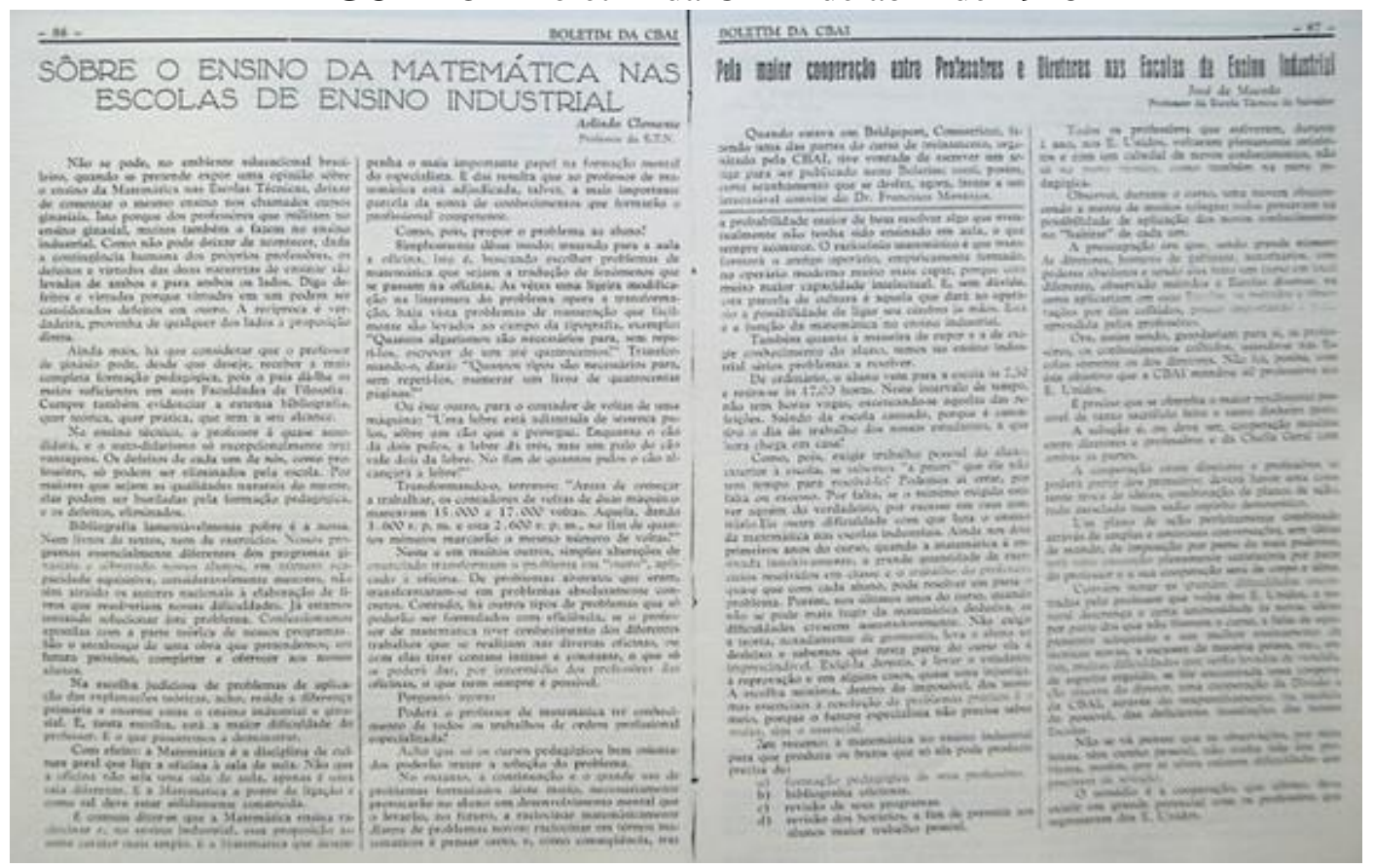

Fonte: Acervo dos autores

Com o título de "Sôbre o ensino de Matemática nas Escolas de Ensino Industrial", Arlindo Clemente afirma que "A Matemática é a disciplina da cultura geral que liga a oficina à sala de aula”. Mas adiante, o autor expõe que:

É comum dizer-se que a Matemática ensina raciocinar e, no ensino industrial, essa proposição assume caráter mais amplo. É a Matemática que desempenha o mais importante papel na formação mental do especialista. E daí resulta que ao professor de matemática está adjudicada, talvez, a mais importante parcela da soma de conhecimentos que formarão o profissional competente (BOLETIM DA CBAI, 1948, p. 86).

Ainda neste Boletim, há sugestões de como se alterar o enunciado de um problema para se trabalhar numa sala de aula do ensino industrial: "Exemplo: 'Quantos algarismos são necessários para, sem repeti-los, escrever de um até quatrocentos?' Transformando-o, dará: 'Quantos tipos são necessários para, sem repeti-los, numerar um livro de quatrocentas páginas?" O excerto, ainda, coloca outro exemplo para o contador de voltas de uma máquina:

Uma lebre está adiantada de sessenta pulos, sobre um cão que a persegue. Enquanto o cão dá dois pulos, a lebre dá três, mas um pulo do cão vale dois da lebre. No fim de quantos pulos o cão alcançará a lebre?” Transformando-o,

Rev. Iberoam. Patrim. Histórico-Educativo, Campinas (SP), v. 5, p. 1-17, e019035, 2019. 
teremos: "Antes de começar a trabalhar, os contadores de voltas de duas máquinas marcavam 15.000 e 17.000 voltas. Aquela, dando 3.600 r.p.m. e esta 2.600 r.p.m., no fim de quantos minutos marcarão o mesmo número de voltas? (Ibid., p. 86).

Como coloca Clemente, autor do texto, a modificação da literatura do problema transforma-o em outro, “aplicado à oficina”. Nesta ideia, sugere ele, o problema abstrato deve-se transformar em problema concreto.

Além disso, outro trecho importante fala da função da Matemática no ensino industrial:

O raciocínio matemático é que transformará o antigo operário, empiricamente formado, no operário moderno muito mais capaz, porque com muito maior capacidade intelectual. E, sem dúvida, esta parcela de cultura é aquela que dará ao operário a possibilidade de ligar seu cérebro às mãos. Esta é a função da Matemática no ensino industrial (Ibid., p. 87).

Algumas outras ponderações o autor do texto faz em relação ao conteúdo e aos alunos. "Não exigir a teoria, notadamente de geometria, leva o aluno ao desleixo e sabemos que nessa parte do curso ela é imprescindível. Exigi-la demais, é levar o estudante à reprovação e em alguns casos, quase uma injustiça” (Ibid., p. 87). É possível perceber que há uma preocupação de como deve ser a relação da matemática nas classes de ensino industrial. Para concluir, Arlindo Clemente faz uma observação:

Em resumo: a matemática no ensino industrial para que produza os frutos que só ela pode produzir precisa de:

a) formação pedagógica de seus professôres;

b) bibliografia eficiente;

c) revisão de seus programas;

d) revisão dos horários, a fim de permitir aos alunos maior trabalho pessoal. (Ibid., p. 87).

No Boletim da CBAI Volume VI, n 11 , de novembro de 1952, houve a publicação na coluna "Problema de Educação" de um artigo intitulado "Organização de escolas e cursos de educação vocacional", escrito por Fernando Romero, versão do espanhol do professor Sylvio do Valle Amaral, auxiliar-técnico da CBAI. A figura abaixo mostra a publicação do artigo: 
FIGURA 4 - Boletim da CBAI de novembro de 1952

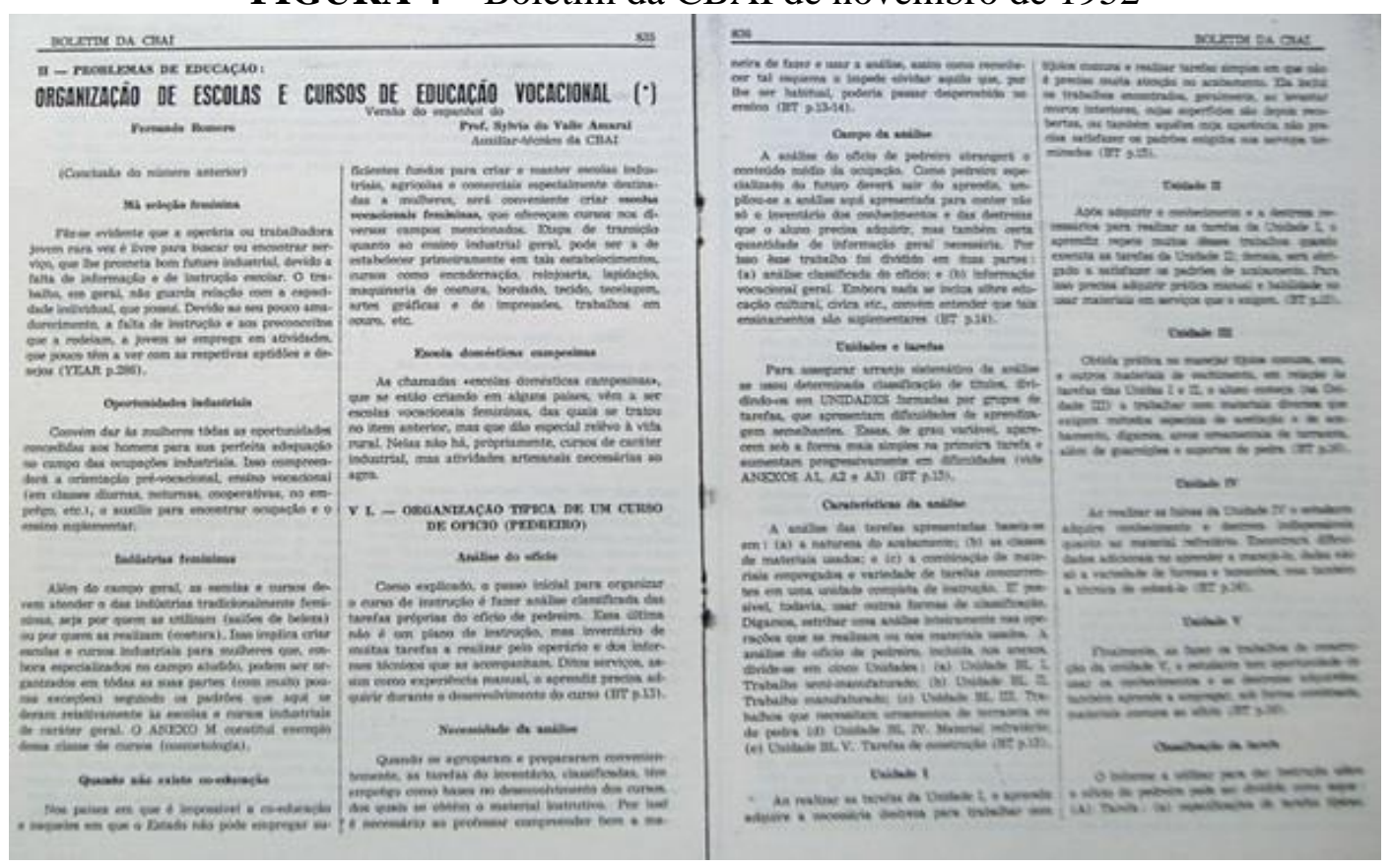

Fonte: Acervo dos autores

No item VI, há uma organização típica de um curso de ofício (pedreiro). Ao que tudo indica, o texto nada mais é do que uma "sugestão curricular" para constituição de um curso para "Pedreiros". Das diversas orientações constantes, destacar-se-á o que diz respeito à Matemática.

$\mathrm{O}$ artigo sugere que a cada problema com enunciado matemático, o aluno deve aprender a resolver para que realize alguma tarefa. Ele indica que sejam incluídas sugestões de formas de resolvê-los. Assim diz o texto original:

Cada especificação típica do trabalho é acompanhado de um enunciado de problemas matemáticos, que o estudante aprenderá a resolver para realizar uma ou mais tarefas. Esses problemas se dão em termos matemáticos e incluem sugestões relativas a forma de resolvê-los. Também se fornecem dispositivos especiais a usar na respetiva solução (BOLETIM DA CBAI, 1952, p. 838).

Importante destacar que há dois títulos relacionados à Matemática: um, de nome "Matemática", local de onde foi retirado o excerto acima; e o outro intitulado "Matemática não essencial", passagem na qual o autor do trecho afirma que "Os assuntos geométricos, por exemplo, podem apresentar-se e os problemas são resolvidos sem que o aprendiz receba curso formal de geometria" (Ibid., p. 838).

Rev. Iberoam. Patrim. Histórico-Educativo, Campinas (SP), v. 5, p. 1-17, e019035, 2019. 

denominações álgebra, aritmética ou geometria. Abaixo o trecho ${ }^{1}$ onde houve a diferenciação entre matemática e matemática não essencial:

FIGURA 5 - Boletim da CBAI de novembro de 1952

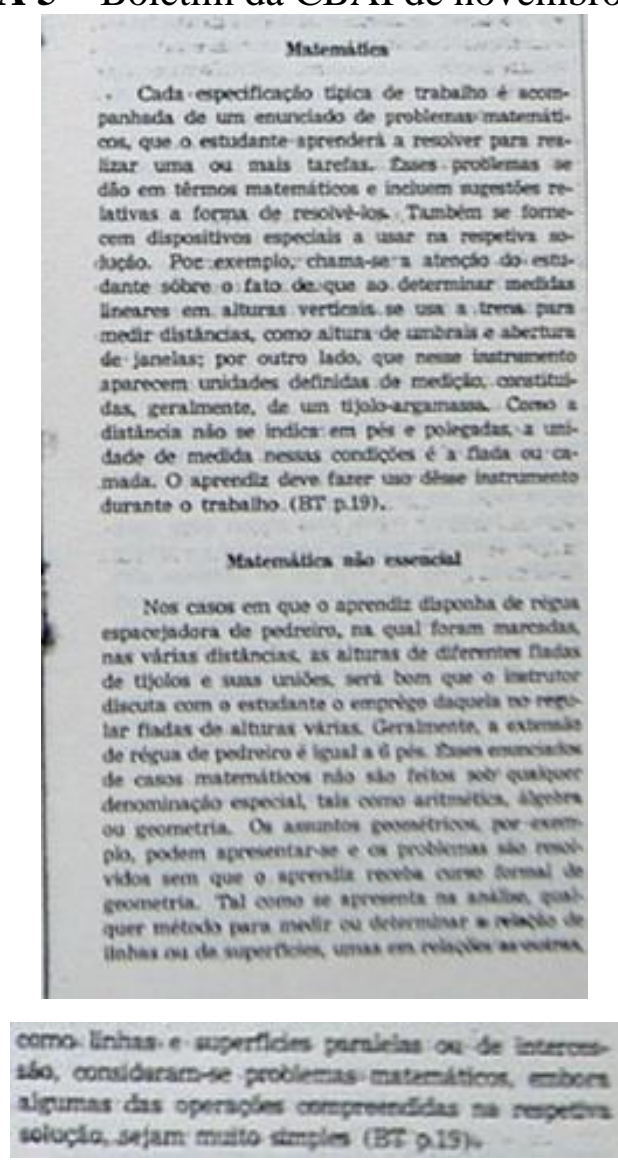

Fonte: Acervo dos autores

${ }^{1}$ Optou-se por realizar a transcrição do trecho constante da imagem, pois a mesma não se encontra em boa resolução: Matemática. Cada especificação típica de trabalho é acompanhada de um enunciado de problemas matemáticos, que o estudante aprenderá a resolver para realizar uma ou mais tarefas. Esses problemas se dão em termos matemáticos e incluem sugestões relativas a forma de resolvê-los. Também se fornecem dispositivos especiais a usar na respectiva solução. Por exemplo, chama-se a atenção do estudante sobre o fato de que ao determinar medidas lineares em alturas verticais se usa a trena para medir distâncias, como altura de umbrais e abertura de janelas; por outro lado, que nesse instrumento aparecem unidades definidas de medição, constituídas, geralmente, de um tijolo-argamassa. Como a distância não se indica em pés e polegadas, a unidade de medida nessas condições é a fiada ou camada. O aprendiz deve fazer uso desse instrumento durante o trabalho (BT, p. 19). Matemática não essencial. Nos casos em que o aprendiz disponha de régua espacejadora de pedreiro, na qual foram marcadas, nas várias distâncias, as alturas de diferentes fiadas de tijolos e suas uniões, será bom que o instrutor discuta com o estudante o emprego daquela no regular fiadas de alturas várias. Geralmente, a extensão de régua de pedreiro é igual a 6 pés. Esses enunciados de casos matemáticos não são feitos sob qualquer denominação especial, tais como aritmética, álgebra ou geometria. Os assuntos geométricos, por exemplo, podem apresentar-se e os problemas são resolvidos sem que o aprendiz receba curso formal de geometria. Tal como se apresenta na análise, qualquer método para medir ou determinar a relação de linhas ou de superfícies, umas em relação as outras, como linhas e superfícies paralelas ou de intersecção, consideramse problemas matemáticos, embora algumas das operações compreendidas na respectiva solução, sejam muito simples (BT, p. 19).

Rev. Iberoam. Patrim. Histórico-Educativo, Campinas (SP), v. 5, p. 1-17, e019035, 2019. 
O próximo Boletim a ser analisado é o de Volume 5, n 7, de julho de 1951. O artigo em questão intitula-se “A Matemática na prática e no ensino”, escrito por Angelo Martignoni. Nele há uma série de comentários a respeito do ensino de matemática.

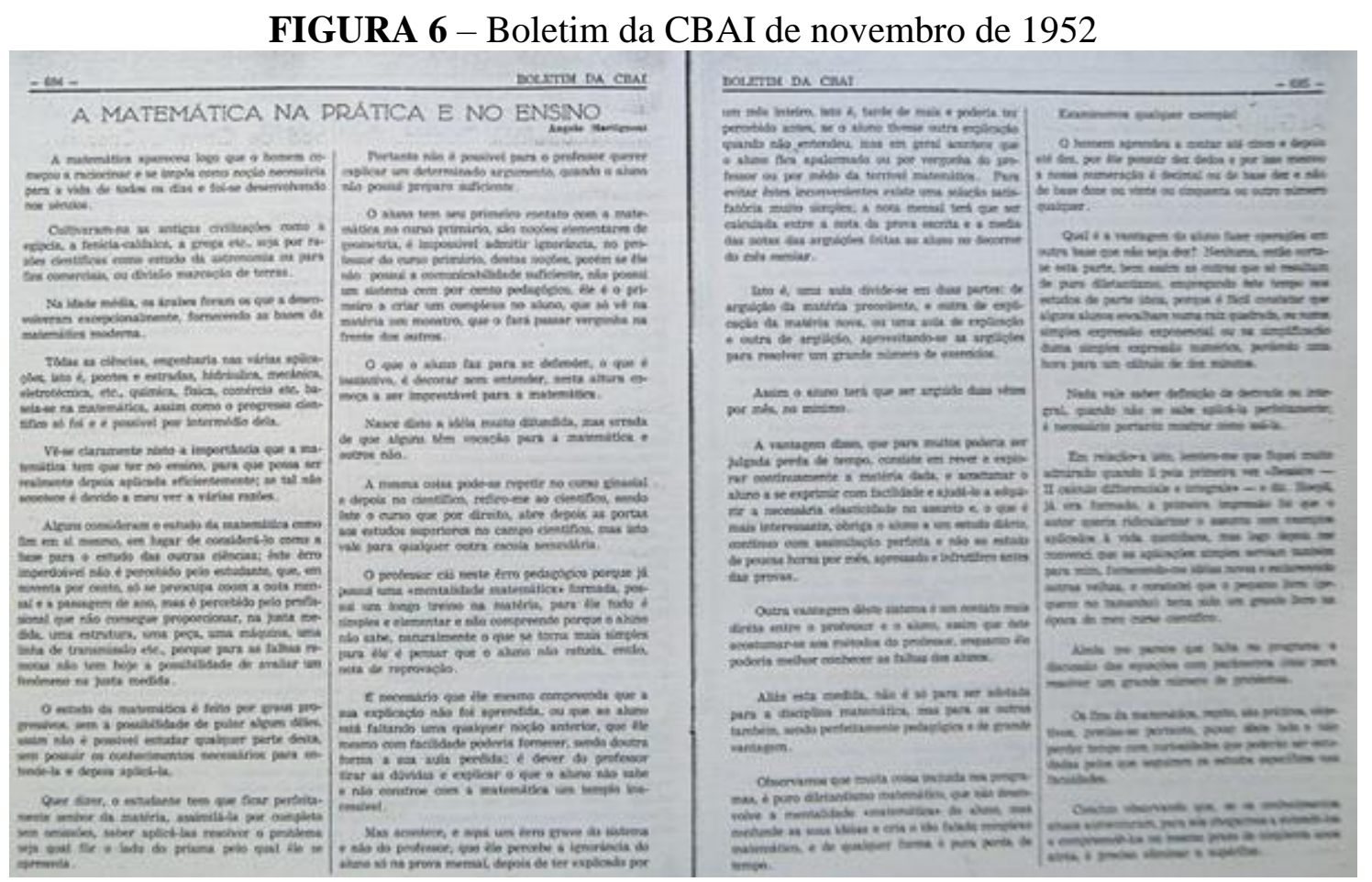

Fonte: Acervo dos autores

De acordo com o autor, “O Estudo da Matemática é feito por graus progressivos, sem a possibilidade de pular algum deles, assim não é possível estudar qualquer parte desta, sem possuir os conhecimentos necessários para entendê-la e depois aplica-la.” (BOLETIM DA CBAI, 1951, p. 694). Mais adiante, conclui o autor, que "não é possível para o professor querer explicar um determinado argumento, quando o aluno não possui preparo suficiente”. (Ibid., p. 694).

Explica, ainda, que o aluno faz para se defender, é "decorar sem entender, nesta altura começa a ser imprestável para a matemática". É, segundo o autor, aí que nasce a ideia de que Matemática não é para todos!

Ao registrar que a aula é dividida em duas partes, ou seja, a de revisão da aula anterior e a nova matéria da aula atual, dá como recado que "Assim, o aluno terá que ser arguido duas vezes por mês, no mínimo" (Ibid., p. 695). Em sua conclusão, Martignoni deixa claro que "Os fins da matemática, repito, são práticos, objetivos, precisa-se portanto, puxar deste lado e não perder tempo com 
curiosidade que poderão ser estocadas pelos que seguirem os estudos específicos mas faculdades. (Ibid., p. 695).

Percebe-se, portanto, que os Boletins trouxeram reflexões acerca do ensino de Matemática para as Escolas Industriais. O que se pode concluir deste último excerto é que a Matemática poderia, sim, ser para todos. Bastaria mudar o modo de funcionamento das aulas.

\section{CONSIDERAÇÕES FINAIS}

O trabalho se propôs a verificar de que modo os Boletins da $\mathrm{CBAI}^{2}$ podiam ser encarados como materiais ou instrumentos ou dispositivos para o ensino de Matemática, em particular, nas escolas de Ensino Industrial. A partir de seus objetivos definidos, a CBAI tinha o propósito de modificar e melhorar o ensino industrial no Brasil, a partir dos modelos norte-americanos.

Dentre muitas finalidades, a intenção da impressão e distribuição dos Boletins da CBAI foi a estratégia de se levar as notícias a todas as Escolas Industriais brasileiras, espalhadas em todo o território nacional.

Neste artigo, os Boletins da CBAI foram considerados "materiais para o ensino", mais especificamente, para o ensino de Matemática para as Escolas Industriais. A partir da leitura e das interpretações, pode-se verificar a importância que os jornais/boletins têm para a história da Educação e, é claro, para a História da Educação Matemática.

Os Boletins analisados mostram uma preocupação especial como o ensino de Matemática. Os textos publicados trazem instruções de funcionamento das aulas, alteração de enunciados, dentre outros, sempre aplicado à oficina, ou seja, ao cotidiano de um aluno de uma escola industrial.

Como escrito no texto, houve a publicação de 150 Boletins durante todo o período de existência da CBAI. Neste trabalho, foram analisados somente quatro. Restando para os futuros trabalhos de se conseguir analisar os demais Boletins e verificar quais outras leituras e interpretações podem ser dados no que diz respeito ao ensino de Matemática para as escolas de ensino industrial.

\footnotetext{
${ }^{2}$ Os autores manifestam agradecimentos especiais à Professora Bárbara Winiarski Diesel Novaes e ao Professor Mário Lopes Amorim, da Universidade Tecnológica Federal do Paraná (UTFPR) pelo compartilhamento dos Boletins da CBAI.
} 
Verifica-se, portanto, que os Boletins da CBAI podem ser considerados divulgadores de saberes pedagógicos e disciplinares para o Ensino Industrial Brasileiro, em particular àqueles ligados à Matemática.

\section{REFERÊNCIAS}

AMORIM, Mário Lopes. O surgimento da Comissão Brasileiro-Americana de Educação Industrial (CBAI). História da Educação, v. 11, n. 23, p. 149-171, 2007. Disponível em: http://seer.ufrgs.br/index.php/asphe/article/view/29275.

BASTOS, Maria Helena Camara. A imprensa de educação e de ensino: repertórios analíticos. O exemplo da França. Revista Brasileira de Educação, v. 12, n. 34, p. 166-168, 2007.

BORDIGNON, Talita. A CBAI e o "intento diferenciador" por meio do ensino técnico a partir de

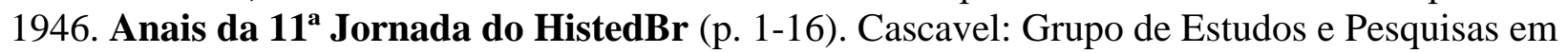
"História, Sociedade e Educação no Brasil" - GT da Região Oeste do Paraná - HISTEDOPR, e Programa de Desenvolvimento da Educação - PDE, 2013. Retirado em 19 de novembro, 2018, de:

http://www.histedbr.fe.unicamp.br/acer_histedbr/jornada/jornada11/artigos/2/artigo_simposio_2 989_tatabordignon@gmail.com.pdf

BORGES, Rosimeire Aparecida Soares. Revistas pedagógicas: fontes para a pesquisa em história da educação matemática. In VALENTE, Wagner Rodrigues (Org.). História da Educação Matemática no Brasil: problemáticas de pesquisa, fontes, referências teórico-metodológicas e histórias elaboradas. São Paulo: Editora Livraria da Física, 2014, pp. 246-258.

COMISSÃO BRASILEIRO-AMERICANA DE EDUCAÇÃO INDUSTRIAL (CBAI). Boletim da CBAI, v. 2, n. 4. CBAI: Rio de Janeiro, 1948.

COMISSÃO BRASILEIRO-AMERICANA DE EDUCAÇÃO INDUSTRIAL (CBAI). Boletim da CBAI, v. 6, n. 11. CBAI: Rio de Janeiro, 1952.

COSTA, Reginaldo Rodrigues da. A pesquisa em história da educação matemática: um panorama das pesquisas apresentadas no XI Encontro Nacional de Educação Matemática. HISTEMAT, v. 3, n. 2, p. 23-40, 2017.

FLORES, Cláudia Regina. Como a matemática foi engendrada, em tempos passados, nos anos iniciais da escolaridade? In VALENTE, Wagner Rodrigues (Org.). História da Educação Matemática no Brasil: problemáticas de pesquisa, fontes, referências teórico-metodológicas e histórias elaboradas. São Paulo: Editora Livraria da Física, 2014, pp. 50-61.

FONSECA, Celso Suckow da. Historia do ensino industrial no Brasil. Rio de Janeiro: Nacional, 1986. 
GARNICA, Antônio Vicente Marafioti. Outras inquisições: apontamentos sobre História Oral e História da Educação Matemática. Zetetiké, v. 18, n. 2, p. 259-304, 2010.

GOMES, Maria Laura Magalhães. História da formação de professores que ensinam Matemática: no livro de memórias de uma professora paulista. HISTEMAT, v. 2, n. 3, p. 117-133, 2016.

MACIEL, Paulo Roberto Castor. A Matemática na Escola Técnica Nacional (1942-1965):Uma disciplina diferente? 2018. 216p. Tese de Doutorado em Ciência, Tecnologia e Educação. Centro Federal de Educação Tecnológica Celso Suckow da Fonseca, CEFET/RJ, Rio de Janeiro. Retirado em 19 de novembro, 2018, de: https://sucupira.capes.gov.br/sucupira/public/consultas/coleta/trabalhoConclusao/viewTrabalhoC onclusao.jsf?popup=true\&id_trabalho=6278183.

MELO, Cristiane. Silva. A utilização da legislação educacional e da imprensa periódica como fontes para a História da Educação: aspectos teóricos, metodológicos e interpretativos. Anais do Congresso Nacional de Educação (EDUCERE), Curitiba, PR, Brasil, 13, 2017.

MIGUEL, Antonio. O que dizem os estudos já elaborados sobre a emergência da história da educação matemática no Brasil? In VALENTE, Wagner Rodrigues (Org.). História da Educação Matemática no Brasil: problemáticas de pesquisa, fontes, referências teóricometodológicas e histórias elaboradas. São Paulo: Editora Livraria da Física, 2014, pp. 30-45.

PINTO, Neusa Bertoni; NOVAES, Bárbara Winiarski Diesel. A apropriação da Matemática Moderna na escola Técnica Federal do Paraná nas décadas de 60 e 70 . Rev. Diálogo Educ., v. 8, n. 25, p. 745-762, 2008.

PROHMANN, Mariana. Americanismo e Fordismo nos Boletins da Comissão Brasileiro Americana de Educação Industrial. 2016. 199p. Dissertação de Mestrado em Tecnologia. Universidade Tecnológica Federal do Paraná, Curitiba. Retirado em 19 de novembro, 2018, de: http://repositorio.utfpr.edu.br/jspui/bitstream/1/1658/1/CT_PPGTE_M_Prohmann\%2c\%20Maria na_2016.pdf.

SOUZA, Luzia Aparecida de; GARNICA, Antônio Vicente Marafioti. Arquivos e fontes, escrita e oralidade, infância e velhice: considerações acerca de um protocolo de pesquisa sobre um Grupo Escolar. R. Educ. Públ., v. 22, n. 50, p. 763-784, 2013.

VALENTE, Wagner Rodrigues. Oito temas sobre história da educação matemática. REMATEC, ano 8, n. 12, p. 22-50, 2013.

Recebido em: 30 de julho de 2019 Aceito em: 22 de dezembro de 2019 